DOI: $10.12731 / 2070-7568-2020-1-125-145$

УДК 331.105

\title{
ИННОВАЦИОННЫЙ МЕНЕДЖМЕНТ : К ВОПРОСУ О ПОВЫШЕНИИ ИННОВАЦИОННОЙ ВОСПРИИМЧИВОСТИ ПЕРСОНАЛА
}

\author{
Кутузова А.В., Яркова С.А., Якимова Л.Д., \\ Мельникова Е.В.
}

Цель настоямего прикладного исследования состояла в выборе управленческих решений по снижению сопротивления персонала железнодорожной организачии внедрению инноваций. B статье проведено исследование понятия «инновачионная восприимчивость», ее роль для инновационного менеджмента предприятий железнодорожной отрасли. С помощью методики Е.А. Ларичевой выявлен уровень инновачионной восприимчивости работников локомотивных бригад Эксплуатационного локомотивного депо. Обоснована необходимость разработки системы управления инновационной восприимчивостью персонала. Разработан проект мероприятий по повышению инновационной восприимчивости рабочих локомотивных бригад исследуемого депо до среднего уровня, предполагающего наличие специалистов, способных осуществлять инновационную деятельность и проводить исследования, а так же способности персонала использовать результаты научных разработок других организаций, осуществлять управление инновачионным прочессом. Проект включает мероприятия по разработке программы развития компетенциии рабочих по исследуемой проблеме; по внедрению системы стимулирования инновачионной активности и создание информаџионной программы о планируемых инновациях. Выполнена оченка сочиального и экономического эффекта проекта. Выявлены вероятности рисков, связанных с предложенными мероприятиями. Подсчитана общая экономия затрат за счет условного высвобождения работников локомотивных бригад. Предложенная система управления инно- 
вачионной восприимчивостью персонала может быть использована на аналогичных предприятиях железнодорожной отрасли.

Ключевые слова: инновационный менеджмент; инновация; инновачионная восприимчивость персонала; проект; железнодорожный транспорт.

\section{INNOVATIVE MANAGEMENT: TO THE QUESTION OF INCREASING INNOVATIVE SUSTAINABILITY OF PERSONNEL}

\section{Kutuzova A.V., Yarkova S.A., Yakimova L.D., Melnikova E. V.}

The aim of the present research is to find managerial solutions for decreasing the resistance of the railway personnel to innovations. The article investigates the concept of "innovative receptivity", its role for innovative management of railway industry companies. Innovative receptivity level of locomotive brigades at the Operating Locomotive Depot is proved by E.A. Laricheva's method. Necessity of developing the system of innovative personnel receptivity management is also substantiated. We have developed a project for increasing workers' innovation susceptibility to the average level, which implies the presence of specialists capable to carry out innovative activities and research, as well as the ability of the staff to use the scientific advances of other organizations for managing the innovation process. Our project includes: activities to design a program for the relevant competencies of workers increasing; activities to implement a stimulation of the innovative activity system and development of an information program regarding planned innovations. The social and economic effect of the project was evaluated and the probabilities of risks associated with the proposed activities were identified. We also calculated total cost savings due to the relative freeing-up of the locomotive crews'employees. The proposed system for managing the innovative receptivity of personnel can be used at similar railway companies.

Keywords: innovation management; innovation; innovative staff susceptibility; project; railway transport. 


\section{Введение}

Инновационные изменения внешней среды (глобализация и цифровизация экономики, внедрение новых технологий, демографические тренды и усиление конкурентной борьбы за таланты), необходимость развития внутренней среды и корпоративной культуры, новые стратегические задачи являются неотъемлемым рычагом развития любого современного предприятия $[2,12,14,15]$.

Стратегии, утвержденные в Долгосрочной программе развития ОАО «РЖД» до 2025 года, стали предпосылками для пересмотра модели корпоративных компетенций холдинга. Согласно новой модели, сотрудник ОАО «РЖД» должен быть ориентирован, прежде всего, на инновативность, клиентоориентированность, ответственность за результат. Он должен обеспечивать организацию рабочего процесса, командную работу и взаимовыручку, развитие и заботу о сотрудниках. Ему необходимо обладать комплексным мышлением и осуществлять эффективные коммуникации. Обновленная модель корпоративных компетенций свидетельствует о том, что роль персонала в холдинге возрастает. Компетенция «Инновативность» усилена поведенческими индикаторами, направленными на успешную реализацию цифровых проектов компании, предполагающих повышение вовлеченности сотрудников в инновационную деятельность. Развитие инновационного потенциала персонала в настоящее время является важной задачей предприятий разных сфер экономики $[5,13,16,17]$.

Инновационный менеджмент компании регламентируется отраслевыми стандартами $[7,9]$. В частности стандарт «СТО РЖД 08.013-2011 Инновационная деятельность в ОАО «РЖД». Общие положения» содержит следующие корпоративные механизмы, способствующие созданию и внедрению инноваций:

- технологического развития компании (концепции технологической политики и политики в сфере информатизации, программы совершенствования системы разработки и проектирования продукции, программы повышения энергоэффективности);

- подготовка и внедрение планов научно-технического и инновационного развития, инновационных политик и иных управ- 
ляющих документов, регламентирующих работу в сфере инновационной деятельности;

- эффективная организация НИОКР, как за счет инновационных идей, создаваемых внутри компании, так и за счет заимствования потенциала сторонних предприятий и компаний, в том числе на лицензионной основе;

- формирование системы управления интеллектуальной собственностью (патенты, лицензии, ноу-хау).

В соответствии с обновленной моделью корпоративных компетенций инновационная политика, регламентирующая работу в сфере инновационной деятельности, должна быть усилена проведением мероприятий по повышению инновационной восприимчивости персонала предприятий железнодорожной отрасли.

Исходя из стратегических задач развития холдинга ОАО «РЖД» цель настоящего прикладного исследования состояла в выборе управленческих решений по снижению сопротивления персонала железнодорожной организации внедрению инноваций.

\section{Материалы и методы}

Исследованием менеджмента инноваций занимались такие авторы, как М.А. Горохова, А.А. Никоноров, Е.А. Карпова [2], Е.А. Ларичева [3], Л.А. Мыльникова [5], О.Н. Осипова [6] и др. Подчеркивая важность данной проблемы, М.А. Горохова, А.А. Никоноров, Е.А. Карпова понимают инновационные трансформации малых и больших социально-экономических систем как двигатель научнотехнического прогресса и как условие смены научно-технических парадигм управления и стратегическое совершенствование бизнеса. Л.А. Мыльникова рассматривает инновационный потенциал, включающий человеческий капитал, как основной фактор развития и повышения конкурентоспособности страны. Инновационная восприимчивость трактуется О.Н. Осиповой как способность применять пионерные технологические новшества, либо готовность и способность того или иного предприятия осуществлять впервые инновацию. Е.А. Ларичева же рассматривает инновационную восприимчивость 
на уровне работника как способность и осознание им необходимости внедрения инноваций на предприятии. На сегодняшний день, следовательно, не существует устоявшегося определения термина «инновационная восприимчивость», т.к. подавляющее большинство авторов останавливаются на интуитивной интерпретации данного понятия, что приводит к нечеткости и большому разнообразию вкладываемых в него смыслов. В таблице 1 приведено понимание термина «инновационная восприимчивость» разными авторами. Вследствие того, что на предприятиях железной дороги активно внедряются инновации и технология кайдзен, будем использовать при понимании термина «инновационная восприимчивость персонала» трактовку Е.А. Ларичевой.

Таблича 1.

Классификация понятий инновационная восприимчивость

\begin{tabular}{|l|l|}
\hline \multicolumn{1}{|c|}{ Автор } & \multicolumn{1}{|c|}{ Определение } \\
\hline Н.П. Масленникова & $\begin{array}{l}\text { Процесс оценки инновации, инициации ее принятия, } \\
\text { осуществления инновации и рутинизации (превращение } \\
\text { инновации в привычную, которая характеризуется } \\
\text { предсказуемой струкурой поведения работников и } \\
\text { повторяющимися схемами деятельности). }\end{array}$ \\
\hline Т.А. Дементьева & $\begin{array}{l}\text { Умение сотрудников предприятия воспринимать } \\
\text { рекомендации, методы, подходы к тем или иным } \\
\text { новшесвам, предлагаемые специализированными } \\
\text { организациями. }\end{array}$ \\
\hline Р.А. Фатхутдинов & Составляющая для оценки инновационной активности. \\
\hline Л.В. Фильберт & $\begin{array}{l}\text { Степень готовности (стремление и возможности) } \\
\text { предприятия к разработке и реализации инновационных } \\
\text { проектов или программ инновационных преобразований и } \\
\text { внедрения инноваций. }\end{array}$ \\
\hline Е.А. Ларичева & $\begin{array}{l}\text { Творческие и инновационные способности работников, } \\
\text { осознание ими необходимости внедрения инноваций на } \\
\text { предприятии. }\end{array}$ \\
\hline В.П. Горшенин & $\begin{array}{l}\text { Способность работников вырабатывать и эффективно } \\
\text { реализовывать свои и сторонние новые идеи, и проекты. }\end{array}$ \\
\hline Ю.В. Шленов & $\begin{array}{l}\text { Способность к быстрому и эффективному освоению } \\
\text { новшества, побуждению, созданию и внедрению } \\
\text { новаций, восприятию инноваций в целях удовлетворения } \\
\text { потребительского спроса }\end{array}$ \\
\hline О.Н. Осипова & $\begin{array}{l}\text { Способность применять пионерные технологические } \\
\text { новшества, либо готовность и способность того или иного } \\
\text { предприятия осуществлять впервые инновацию }\end{array}$ \\
\hline
\end{tabular}


Формирование системы инновационной восприимчивости персонала является одной из основных задач для руководителей предприятий. Ученые связывают факторы отсутствия системы и низкого уровня инновационной восприимчивости, как преграду внедрения новшествам и предлагают различные методы преодоления данного сопротивления. При проведении анализа уровня инновационной восприимчивости персонала Эксплуатационного локомотивного депо использовалась методика Е.А. Ларичевой [3]. Была выявлена проблема низкого уровня данного показателя у работников локомотивных бригад [10], характеризующаяся степенью выраженности таких мотивов трудовой деятельности, как удовлетворение от работы $(1,43)$ и стремление к самовыражению в труде, желание проявить творчество в работе $(1,43)$. При этом ниже среднего считается ранг менее 1,5 [4].

\section{Разработка и обоснование мероприятий}

Рекомендации и мероприятия для устранения выявленных проблем представлены в таблице 2. Данные мероприятия положены в основу проекта, направленного на повышение уровня инновационной восприимчивости персонала Эксплуатационного локомотивного депо.

Таблица 2.

Проблемы, рекомендации и мероприятия по обоснованию проекта формирования инновационной восприимчивости работников Эксплуатационного локомотивного депо

\begin{tabular}{|c|c|c|}
\hline Проблема & Рекомендация & Мероприятие \\
\hline $\begin{array}{l}\text { Низкий уровень вос- } \\
\text { приимчивости рабочих } \\
\text { к инновационному } \\
\text { процессу оптимизации } \\
\text { производства }\end{array}$ & $\begin{array}{l}\text { Разработать про- } \\
\text { грамму развития } \\
\text { компетенций рабо- } \\
\text { чих по исследуе- } \\
\text { мой проблеме } \\
\end{array}$ & $\begin{array}{l}\text { Разработать программу развития } \\
\text { компетенции «инновационность» } \\
\text { для рабочих }\end{array}$ \\
\hline $\begin{array}{l}\text { Низкая мотивация ра- } \\
\text { ботников локомотив- } \\
\text { ных бригад к иннова- } \\
\text { ционной активности } \\
\end{array}$ & $\begin{array}{l}\text { Разработать систе- } \\
\text { му стимулирования } \\
\text { инновационной ак- } \\
\text { тивности рабочих } \\
\end{array}$ & $\begin{array}{l}\text { Разработать положение по сти- } \\
\text { мулированию инновационной ак- } \\
\text { тивности работников локомотив- } \\
\text { ных бригад на конкурсной основе }\end{array}$ \\
\hline \begin{tabular}{|l|} 
Недостаточный уро- \\
вень информирования \\
работников о планиру- \\
емых инновациях
\end{tabular} & $\begin{array}{l}\text { Сформировать } \\
\text { систему, повы- } \\
\text { шающую уровень } \\
\text { информирования } \\
\text { работников }\end{array}$ & $\begin{array}{l}\text { Разработать информационную } \\
\text { программу «О планируемых ин- } \\
\text { новационных изменениях» }\end{array}$ \\
\hline
\end{tabular}


Основная задача программы развития компетенции «инновативность» у рабочих заключается в успешном освоении и распространении передового опыта. Таким образом, прогнозируется повышение уровня инновационной восприимчивости работников локомотивных бригад Эксплуатационного локомотивного депо. Мероприятие состоит из следующих шагов:

а) изучение теоретических и методологических аспектов проблемы;

б) разработка программы развития компетенций;

в) утверждение и внедрение программы развития компетенций;

г) реализация программы развития компетенций.

Программа предполагает с помощью 4 этапов выстроить систему развития компетенции «инновативность» для работников локомотивных бригад, при сформированности которой они будут активно участвовать в инновационном процессе оптимизации производства.

1 этап - старт - разработка профиля направлений развития компетенции инновативность у работников локомотивных бригад;

2 этап - методический - разработка регламента проведения встреч для развития данной компетенции;

3 этап - обучение - предполагает проведение часовых мастерклассов и получасовых тренингов еженедельно по вторникам и четвергам, а также демонстрации информационной программы по средам на планерных совещаниях;

4 этап - закрепляющий - самостоятельная работа работников локомотивных бригад, самообучение и посещение технической учебы.

В таблице 3 можно увидеть профиль направлений развития компетенции «инновтивность» по блокам.

Таблицуа 3.

Профиль направлений развития по блокам

\begin{tabular}{|c|c|l|}
\hline № & Название блока & \multicolumn{1}{|c|}{ Составляющие блока } \\
\hline 1 & Основной блок & $\begin{array}{l}\text { Знание теории о новых технологиях } \\
\text { Владение практическим опытом работы с новыми } \\
\text { технологиями } \\
\text { Личная мотивация и отношение к работе }\end{array}$ \\
\hline 2 & Командная работа & $\begin{array}{l}\text { Вовлечение в инновационый процесс } \\
\text { Умение работать в команде } \\
\text { Умение дать обратную связь }\end{array}$ \\
\hline
\end{tabular}


Окончание табл. 3.

\begin{tabular}{|l|l|l|}
\hline 3 & $\begin{array}{l}\text { Ответственное } \\
\text { мышление }\end{array}$ & $\begin{array}{l}\text { Умение схематизировать и кратко излагать суть } \\
\text { инноваций } \\
\text { Умение видеть процесс } \\
\text { Умение осознавать последствия }\end{array}$ \\
\hline 4 & Креативность & $\begin{array}{l}\text { Умение нестандартно мыслить } \\
\text { Уение оперативно находить правильные решения и } \\
\text { необходимую информацию }\end{array}$ \\
\hline 5 & Саморазвитие & $\begin{array}{l}\text { Способность воспринимать новую информацию } \\
\text { Умение давать обратную информацию }\end{array}$ \\
\hline
\end{tabular}

В таблице 4 представлена итоговая программа развития компетенции «инновативность» у работников локомотивных бригад.

Таблица 4.

Программа развития компетенции инновационность

\begin{tabular}{|c|c|}
\hline \multicolumn{2}{|r|}{ Блок №1 - Основной блок } \\
\hline Мастер-классы & $\begin{array}{l}\text { Знание теории о новых технологиях } \\
\text { Владение практическим опытом работы } \\
\text { с новыми технологиями } \\
\end{array}$ \\
\hline Тренинговый день & Личная мотивация и отношение к работе \\
\hline \multicolumn{2}{|r|}{ Блок №2 - Командная работа } \\
\hline $\begin{array}{l}\text { Информационная } \\
\text { программа, } \\
\text { мастер-классы }\end{array}$ & Вовлечение в инновационный процесс \\
\hline Тренинговый день & $\begin{array}{l}\text { Умение работать в команде } \\
\text { Умение передавать знания } \\
\text { Умение дать обратную связь } \\
\end{array}$ \\
\hline \multicolumn{2}{|r|}{ Блок № 3 - Ответственное мышление } \\
\hline Тренинговый день & $\begin{array}{l}\text { Умение схематизировать и кратко излагать } \\
\text { суть инноваций } \\
\text { Умение видеть процесс } \\
\text { Умение осознавать последствия } \\
\end{array}$ \\
\hline \multicolumn{2}{|r|}{ Блок № 4 - Креативность } \\
\hline Тренинговый день & $\begin{array}{l}\text { Умение нестандартно мыслить } \\
\text { Умение оперативно находить правильные решения } \\
\text { и необходимую информацию } \\
\end{array}$ \\
\hline \multicolumn{2}{|r|}{ Блок № 5 - Саморазвитие } \\
\hline $\begin{array}{l}\text { Технические } \\
\text { занятия }\end{array}$ & $\begin{array}{l}\text { Обучаемость } \\
\text { Способность усваивать новую информацию } \\
\text { Умение давать обратную информацию }\end{array}$ \\
\hline
\end{tabular}


Разработка положения по стимулированию инновационной активности работников локомотивных бригад на конкурсной основе предназначена, в первую очередь, для создания благоприятных условий внедрения инноваций, во-вторых, - для определения сподвижников инновационного пути оптимизации производства.

Мероприятие осуществляется с помощью следующих шагов:

a) диагностика существующих мотивационных факторов персонала;

б) разработка системы стимулирования;

в) документированное оформление системы стимулирования;

г) согласование системы стимулирования;

д) ознакомление с конкурсной системой стимулирования;

е) проведение конкурса «Будущее железнодорожного транспорта».

Конкурс «Будущее железнодорожного транспорта» организуется администрацией Эксплуатационного локомотивного депо для работников локомотивных бригад вне зависимости от возраста, стажа работы, класса квалификации. Цель конкурса - определить наиболее активных сподвижников инноваций среди локомотивных бригад Эксплуатационного локомотивного депо, успешно усваивавших новшества.

Задачи конкурса:

- материальное стимулирование локомотивных бригад, активно участвующих в процессе внедрении инноваций;

- вовлечение работников локомотивных бригад в процесс инноваций;

- мотивирование работников локомотивных бригад для дальнейшего профессионального роста и обучения.

Разработка информационной программы «О планируемых инновационных изменениях» предполагает повышение уровня осведомлённости работников, вследствие чего ожидается повышение уровня инновационной восприимчивости к планируемым инновациям. Мероприятие состоит из следующих шагов:

a) подготовка информационной программы;

б) разработка регламента информационной программы; 
в) согласование информационной программы;

г) приказ о внесение программы в регламент планерных совещаний;

д) демонстрация информационной программы.

Цель программы - осведомить всех работников локомотивных бригад с инновационной программой оптимизации Эксплуатационного локомотивного депо. Ответственными за формирование и проведение информационной программы являются инструктор по обучению и специалист отдела кадров.

Задачи программы

- вовлечение работников локомотивных бригад в процесс инноваций;

- исключения неверного понимания инновационных изменений;

- налаживание обратной связи с рабочими для получения максимального эффекта от инновационных внедрений.

Информационная программа должна состоять из наглядной презентации, рассчитанной двухсторонний диалог руководства и работников по планируемым инновационным преобразованиям:

- причины внедрения инновации;

- цели и задачи инноваций;

- этапы освоения инновации;

- ожидаемые результаты;

- сроки проведения.

Таким образом, руководство Эксплуатационного локомотивного депо, с одной стороны, сможет повысить уровень инновационной восприимчивости за счет прозрачности проводимых инноваций, с другой - предоставит возможность работникам локомотивных бригад самим принимать участие в обсуждении оптимального пути внедрения инноваций, тем самым почувствовав свою значимость для предприятия.

Для расчета требуемых сроков и ресурсов реализации проекта системы инновационной восприимчивости персонала осуществлялось структурированное разбиение составляющих мероприятий, представленное на рисунке 1. Как видим на данном рисунке, проект 
состоит из предпроектной и проектной частей, а также непосредственного внедрения проекта, в общей сложности - из 16 операций. Сетевой график предлагаемого проекта системы инновационной восприимчивости персонала для Эксплуатационного локомотивного депо представлен на рисунке 2.

После расчетов длительности выполнения операций в соответствии с назначенными ресурсами и их оптимизацией критический путь проекта составил 194 часа.

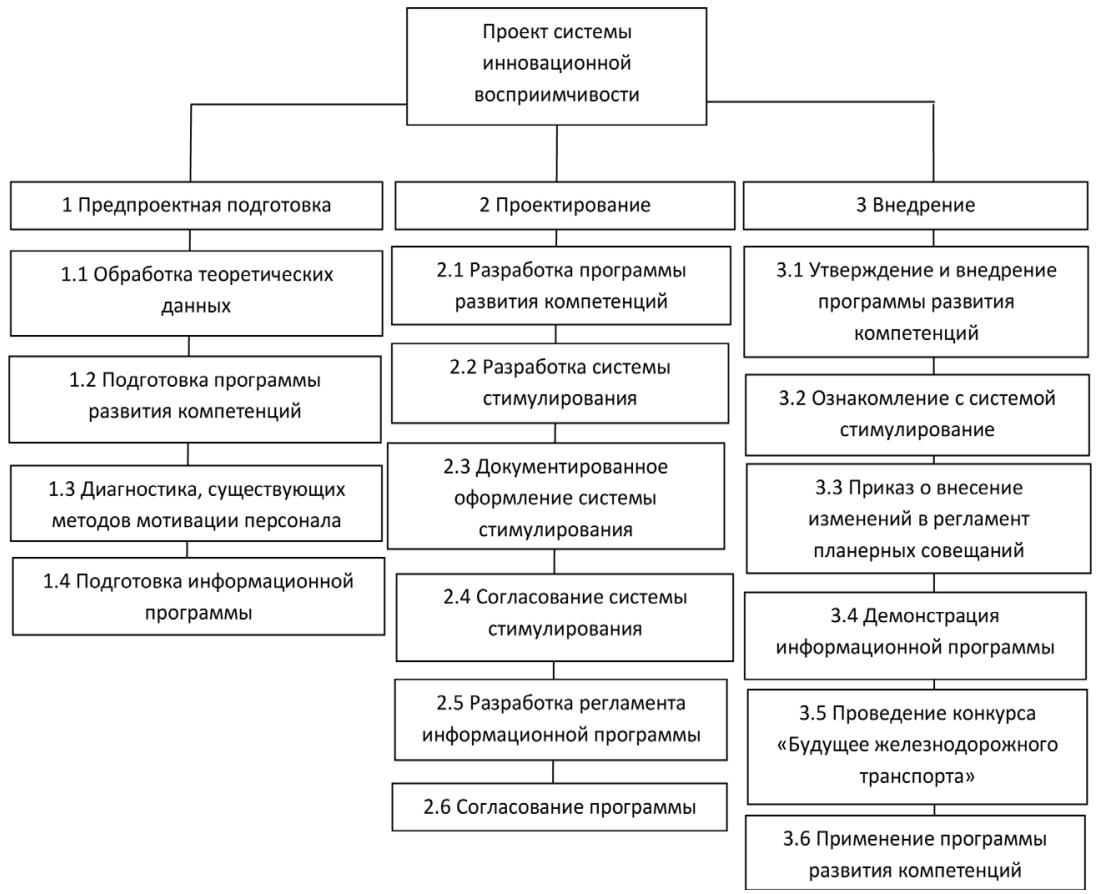

Рис. 1. Структурированное разбиение мероприятий проекта

Расчет экономической эффективности проекта основывался на подсчете требуемых затрат на реализацию предложенных мероприятий по повышению уровня инновационной восприимчивости персонала. Общая стоимость затрат по проекту составила 54835,5 p. 


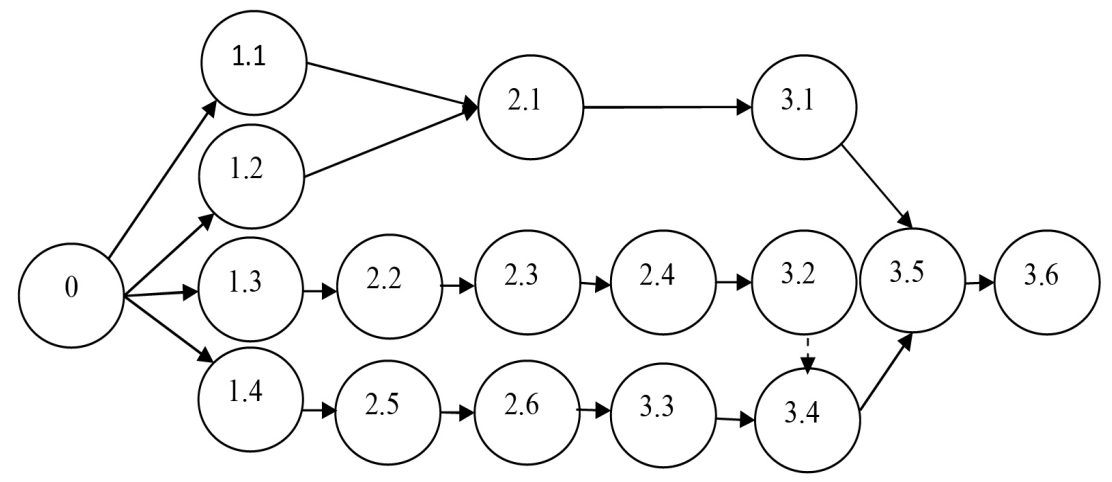

Рис. 2. Сетевой график проекта

При расчете максимально возможного экономического эффекта от внедрения проекта при успешном освоение инновационного процесса оптимизации производства всеми работниками локомотивных бригад, занятыми на перевозках, учитывались все участки обслуживания маршрутов:

$$
\ni_{3}=\left[\left(\Phi_{1}-\Phi_{2}\right) * \Psi * S_{1}\right]
$$

где Э - экономия затрат за счет условного высвобождения рабочих, руб.;

$\Phi_{1}, \Phi_{2}-$ фонд рабочего времени локомотивной бригады в среднем на участок до и после освоения инновационного процесса оптимизации;

$Ч$ - численность рабочих на перевозках;

$S_{1}$ - часовая ставка на перевозках, руб.

Подсчет экономии затрат производился по двум должностям: для машинистов электровозов (Э зм$)$ и помощников машинистов электровозов $\left(Э_{\text {зпм }}\right)$.

$$
\begin{aligned}
& Э_{\text {зм }}=(172-163,76) * 287 * 193,88=458502,93 \text { руб. } \\
& Э_{\text {зпм }}=(172-163,76) * 279 * 142,79=328268,5 \text { руб. } \\
& 458502,93 \text { руб. }+328268,5 \text { руб. }=786771,42 \text { руб. }
\end{aligned}
$$

По результатам расчета показателя «экономия затрат за счет условного высвобождения работников локомотивных бригад» мы видим максимально возможный экономический эффект в 786 771,42 руб. ежемесячно. 
Целесообразно определить изменение уровня инновационной восприимчивости от предложенных мероприятий при помощи проведения анкетирования персонала предприятия в количестве 72 человек, в ходе которого им предлагалась ознакомиться с предложенными мероприятиями по повышению уровня инновационной восприимчивости и оценить их эффективность по пятибалльной шкале, где «5»- очень эффективны, «1»- совсем не эффективны.

Как показал анализ анкет, 14 человек или 19,4\% оценили предложенные мероприятия на «5», 37 человек или 51,4\% - на «4», 11 человек или $15,3 \%$ - на «3», 10 человек или $13,9 \%$ - на «2». Наглядно увидеть полученные результаты эффективности проводимых мероприятий можно на рисунке 3.

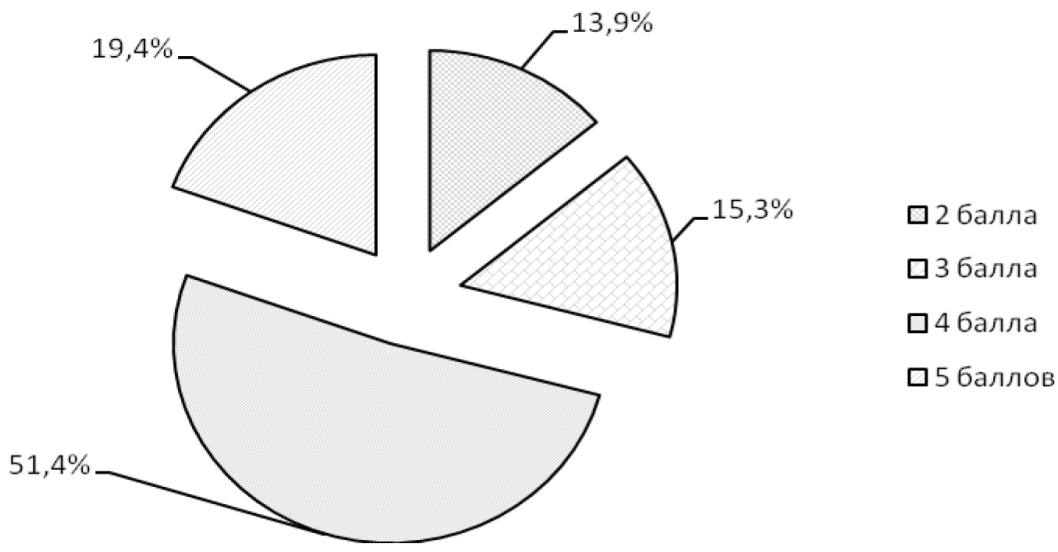

Рис. 3. Эффективность проводимых мероприятий

Таким образом, большинство респондентов, поставивших 4 и 5 баллов (51 человек или 70,8\%), верят в целесообразность разработанных мероприятий и оценили их на очень высоком уровне.

Спрогнозируем изменение уровня инновационной восприимчивости после внедрения проекта системы инновационной восприимчивости работников локомотивных бригад, произведя соотношение среднего балла к максимально возможному баллу. 


$$
\begin{gathered}
V_{\mathrm{cp}}=(5 * 0,194)+(4 * 0,514)+(3 * 0,153)+(2 * 0,139)=3,76 \\
V_{\max }=5 \\
I_{\text {инв }}=V_{\text {ср }} / V_{\max }=3,76 / 5=0,75
\end{gathered}
$$

Теперь, спрогнозировав изменения индекса инновационной восприимчивости работников локомотивных бригад, возможно подсчитать экономический эффект проекта системы инновационной восприимчивости. Обратим внимание на таблицу 5.

Таблициа 5.

Экономический эффект проекта

\begin{tabular}{|l|c|c|c|c|}
\hline & $\begin{array}{c}\text { До внедрения } \\
\left(Э_{\text {ло }}\right)\end{array}$ & $\begin{array}{c}\text { После внедрения } \\
\left(Э_{\text {после }}\right)\end{array}$ & МАХ & $\begin{array}{c}\text { Эффект проекта, } \\
\left(Э_{\text {после }}-Э_{\text {до) }}\right.\end{array}$ \\
\hline$I_{\text {инв }}$ & 0,6 & 0,75 & 1 & - \\
\hline$Э_{\text {зм }}$, pуб. & 275101,76 & 343877,2 & 458502,93 & 68775,44 \\
\hline$Э_{\text {зпм }}$ руб. & 196961,1 & 246201,38 & 328268,5 & 49240,28 \\
\hline$Э_{\text {обш }}$ руб. & 472062,86 & 590078,58 & 786771,42 & 118015,72 \\
\hline
\end{tabular}

Из данных таблицы 6 следует, что после реализации предложенных мероприятий по повышению уровня инновационной восприимчивости работников, общая экономия затрат за счет условного высвобождения работников локомотивных бригад составит 118 015,72 рублей ежемесячно, из них: на машинистах электровозов 68775,44 рублей, на помощниках машинистов электровозов в 49240,28 рублей.

При реализации проекта ожидаются социальные эффекты как для отдельного работника, так и для организации в целом (таблица 6).

\begin{tabular}{|c|c|}
\hline \multicolumn{2}{|c|}{ Социальный эффект } \\
\hline Для организации & Для одного работника \\
\hline $\begin{array}{l}\text { Повышение уровня инновационной вос- } \\
\text { приимчивости персонала } \\
\text { Вовлеченность в инновационный процесс } \\
\text { Повышение производительности труда } \\
\text { Повышение имиджа организации на } \\
\text { рынке труда [11] }\end{array}$ & $\begin{array}{l}\text { Благоприятный социально-психоло- } \\
\text { гический климат } \\
\text { Удовлетворенность работой } \\
\text { Развития компетенций } \\
\text { Материальное и моральное стиму- } \\
\text { лирование }\end{array}$ \\
\hline
\end{tabular}

Таблицуа 6.

\section{Социальный эффект от внедрения предложенных мероприятий}


Проект системы инновационной восприимчивости, как и любой другой проект, связан с определенными рисками $[1,8]$. Для их представления удобно использовать диаграмму Исикавы. Риски, связанные с предложенными мероприятиями, показаны на рисунке 4.

На основе рисунка 4 разработана таблица 7, в которой отражены вероятности и уровни рисков плана проекта системы инновационной восприимчивости персонала.

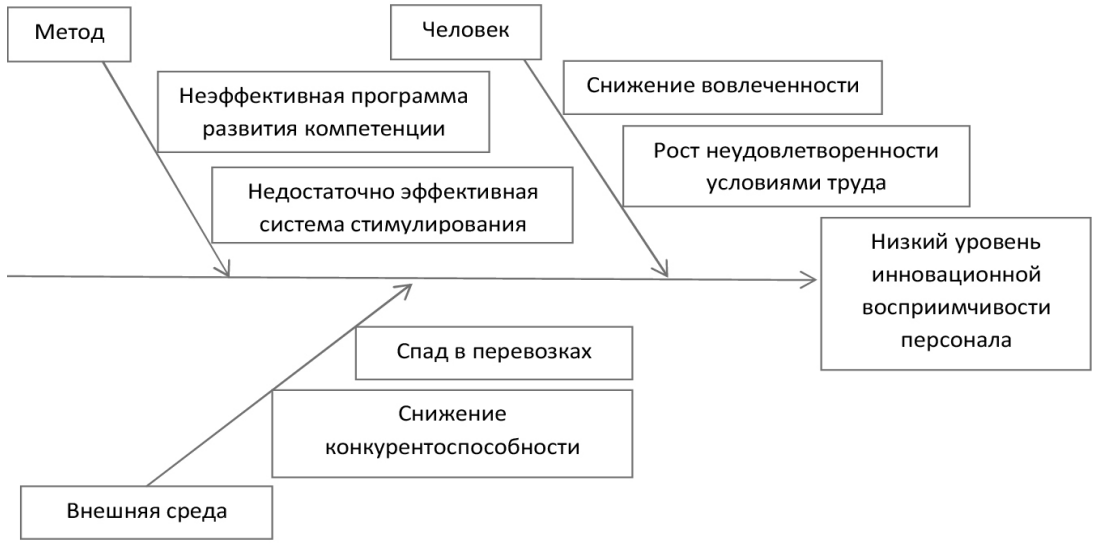

Рис. 4. Диаграмма Исикавы

Таблица 7.

Вероятности и уровни рисков проекта

\begin{tabular}{|c|c|c|c|c|}
\hline $\begin{array}{c}\text { Bероят- } \\
\text { ность }\end{array}$ & \multicolumn{4}{|c|}{ Уровни риска } \\
\hline 5 & $\begin{array}{c}\text { Снижения вовле- } \\
\text { ченности }\end{array}$ & & \\
\hline 4 & $\begin{array}{c}\text { Неэффективная } \\
\text { программа ин- } \\
\text { формирования }\end{array}$ & & & \\
\hline 3 & & $\begin{array}{c}\text { Неэффективная } \\
\text { программа разви- } \\
\text { тия компетенции }\end{array}$ & $\begin{array}{c}\text { Недостаточно эф- } \\
\text { фективная система } \\
\text { стимулирования }\end{array}$ \\
\hline 2 & & $\begin{array}{c}\text { Спад в пе- } \\
\text { ревозках }\end{array}$ & \\
\hline 1 & & $\begin{array}{c}\text { Рост неудовлет- } \\
\text { вонности усло- } \\
\text { виями труда }\end{array}$ & $\begin{array}{c}\text { Снижение конку- } \\
\text { рентоспособности }\end{array}$ \\
\hline & Малые & Средние & Высокие & Катастрофические \\
\hline
\end{tabular}


По результатам опроса и расчетов ожидается, что уровень инновационной восприимчивости работников локомотивных бригад Эксплуатационного локомотивного депо повысится с отметки 0,6 (низкий уровень) до 0,75 (средний уровень). Средний уровень показывает способность персонала использовать результаты научных разработок других организаций, осуществлять управление инновационным процессом традиционной организационной структурой, наличие специалистов, способных проводить инновационную деятельность и исследования.

\section{Заключение}

После реализации предложенных мероприятий общая экономия затрат за счет условного высвобождения работников локомотивных бригад составит 118 015,72 рублей ежемесячно. Предложенная система управления инновационной восприимчивостью персонала может быть использована при организации работы локомотивных бригад на аналогичных предприятиях железнодорожного транспорта.

\section{Список литературы}

1. Бычкова А.А., Никулина Н.Л. Управление рисками как инструмент развития транспортной отрасли в России // Наука Красноярья. 2019. T. 8. № 2. C. 7-21.

2. Горохова М.А., Никоноров А.А., Карпова Е.А. Роль управленческих инноваций в стратегическом развитии компании // Наука Красноярья. 2017. Т. 6. № 2-3. С. 112-115.

3. Ларичева Е.А. Сравнительный анализ корпоративной, инновационной культуры и культуры производства// Менеджмент в России и за рубежом. 2004. №5. С. 263.

4. Ларичева Е.А. Формирование стратегии инновационного развития промышленного предприятия: автореферат дис. кандидата экономических наук: 08.00.05 / Ларичева Елена Анатольевна; [Место защиты: Брянский государственный университет им. акад. И.Г. Петровского]. Брянск, 2006. 24 с. 
5. Мыльникова Л.А. Актуальные проблемы инновационно-ориентированного человеческого капитала в развитии инновационного потенциала страны Наука Красноярья. 2017. Т. 6. № 3-2. С. 210-217.

6. Осипова О.Н., Бороздина Н.С. Оценка и классификация факторов, сдерживающих инновационную восприимчивость региона // Современные наукоемкие технологии. Региональное приложение. 2016. № 2 (26). С. 58-63.

7. Распоряжение ОАО «РЖД» от 26 июня 2012 №1267Р Об утверждении стандартов ОАО «РЖД» по инновационной деятельности, г. Москва.

8. Ратнер С.В., Архипова М.Ю., Нижегородцев Р.М. Эконометрические методы управления рисками инновационных проектов. М., 2016. $272 \mathrm{c}$.

9. Терешина Н.П., Дедова И.Н., Соколов Ю.И., Подсорин В.А. Управление инновациями на железнодорожном транспорте. М., 2015. 304 с.

10. Яркова С.А., Якимова Л.Д. Оценка уровня инновационной восприимчивости персонала // East European Scientific Journal (Warsaw, Poland) № 10 (50), 2019 part 7.86 с. C. 72-76.

11. Яркова С.А., Романцова Ю.Д., Якимова Л.Д., Малахова А.А. Анализ формирования имиджа организации-работодателя на рынке труда как фактора привлечения потенциальных работников // Наука Красноярья. 2018. Т. 7. № 2. С. 7-25.

12. Яркова С.А., Якимова Л.Д., Варламова Е.Г. Управление персоналом в условиях реструктуризации предприятий железнодорожной отрасли // Управление персоналом и интеллектуальными ресурсами в России. 2017. Т. 6. № 6. С. 66-77.

13. Halvarsson Lundkvist A. \& Gustavsson M. Vocations and Learning (2018) 11: 45. https://doi.org/10.1007/s12186-017-9179-6

14. Ionescu C. (2017). The role of organizational culture in enhancing innovation potential. consequences on the market performance of romanian firms. Eastern European Business and Economics Journal, 3(2), pp. 162-175.

15. Lapitskaya L., \& Yemelyanchenko Y. (2019). The economic essence of innovative susceptibility of the organization. University Economic Bulletin, (43), 20-27. https://doi.org/10.31470/2306-546X-2019-43-20-27 
16. Tetiana H., Karpenko L.M., Olesia F.V., Yu S.I., \& Svetlana D. (2018a). Innovative model of enterprises personnel incentives evaluation. Academy of Strategic Management Journal, 17(3), 1-6.

17.Zhang Y., Zhang J., Forest J., \& Chen C. (2018). The Negative and Positive Aspects of Employees' Innovative Behavior: Role of Goals of Employees and Supervisors. Frontiers in psychology, 9, 1871. doi:10.3389/ fpsyg.2018.01871.

\section{References}

1. Bychkova A.A., Nikulina N.L. Upravlenie riskami kak instrument razvitiya transportnoy otrasli v Rossii [The problem of youth employment in the context of the discrepancy between the educational services market and the labor market]. Nauka Krasnojar'ja [Science of Krasnoyarsk], 2019, no. 8 (2), pp. 7-21.

2. Gorokhova M.A., Nikonorov A.A., Karpova E.A. Rol' upravlencheskikh innovatsiy v strategicheskom razvitii kompanii [The role of managerial innovation in the strategic development of the company]. Nauka Krasnojar 'ja [Science of Krasnoyarsk], 2017, no. 6 (2-3), pp. 112-115.

3. Laricheva E.A. Sravnitel'nyy analiz korporativnoy, innovatsionnoy kul'tury i kul'tury proizvodstva [Comparative analysis of corporate, innovative culture and production culture]. Menedzhment $v$ Rossii $i$ za rubezhom [Management in Russia and abroad], 2004, no. 5, p. 263.

4. Laricheva, E.A. Formirovanie strategii innovatsionnogo razvitiya promyshlennogo predpriyatiya [Formation of a strategy for innovative development of an industrial enterprise] : 08.00.05, Bryansk, 2006. $24 \mathrm{p}$.

5. Myl'nikova L.A. Aktual'nye problemy innovatsionno-orientirovannogo chelovecheskogo kapitala $\mathrm{v}$ razvitii innovatsionnogo potentsiala strany [Actual problems of innovation-oriented human capital in the development of the country's innovative potential] Nauka Krasnoyar'ya [Science of Krasnoyarsk], 2017, no. 6 (3-2), pp. 210-217.

6. Osipova O.N., Borozdina N.S. Otsenka i klassifikatsiya faktorov, sderzhivayushchikh innovatsionnuyu vospriimchivost' regiona [Evaluation and classification of factors restraining the innovative susceptibility of 
the region] Sovremennye naukoemkie tekhnologii. Regional'noe prilozhenie [Modern high technology. Regional application]. 2016, no 2 (26), pp. 58-63.

7. Rasporyazhenie $O A O$ «RZhD» ot 26 iyunya 2012 №1267P Ob utverzhdenii standartov $O A O$ «RZhD» po innovatsionnoy deyatel'nosti [Order of JSC Russian Railways dated June 26, 2012 No. 1267P On approval of the standards of JSC Russian Railways for innovative activities]. Moscow.

8. Ratner S.V., Arkhipova M.Yu., Nizhegorodtsev R.M. Ekonometricheskie metody upravleniya riskami innovatsionnykh proektov [Econometric methods of risk management of innovative projects]. Moscow, 2016, $272 \mathrm{p}$.

9. Tereshina N.P., Dedova I.N., Sokolov Yu.I., Podsorin V.A. Upravlenie innovatsiyami na zheleznodorozhnom transporte [Innovation Management in Rail Transport]. Moscow, 2015, 304 p.

10. Yarkova S.A., Yakimova L.D. Otsenka urovnya innovatsionnoy vospriimchivosti personala [Assessment of the level of innovative staff susceptibility]. East European Scientific Journal (Warsaw, Poland), no. 10 (50), 2019, part 7, pp. 72-76.

11. Yarkova S.A., Romancova Ju.D., Yakimova L.D., Malahova A.A. Analiz formirovanija imidzha organizacii-rabotodatelja na rynke truda kak faktora privlechenija potencial'nyh rabotnikov [Analysis of the image of the employer organization in the labor market as a factor in attracting potential employees]. Nauka Krasnojar'ja [Science of Krasnoyarsk], 2018, no. 7 (2), pp. 7-25.

12. Yarkova S.A., Yakimova L.D., Varlamova E.G. Upravlenie personalom v uslovijah restrukturizacii predprijatij zheleznodorozhnoj otrasli [Personnel management in the context of the restructuring of the railway industry]. Upravlenie personalom i intellektual'nymi resursami v Rossii [Personnel and intellectual resources management in Russia], 2017, no. 6 (6), pp. 66-77.

13. Halvarsson Lundkvist A. \& Gustavsson M. Vocations and Learning (2018) 11: 45. https://doi.org/10.1007/s12186-017-9179-6

14. Ionescu C. (2017). The role of organizational culture in enhancing innovation potential. consequences on the market performance of roma- 
nian firms. Eastern European Business and Economics Journal, 3(2), $162-175$.

15.Lapitskaya L., \& Yemelyanchenko Y. (2019). The economic essence of innovative susceptibility of the organization. University Economic Bulletin, (43), 20-27. https://doi.org/10.31470/2306-546X-2019-43-20-27

16. Tetiana H., Karpenko L.M., Olesia F.V., Yu S.I., \& Svetlana D. (2018a). Innovative model of enterprises personnel incentives evaluation. Academy of Strategic Management Journal, 17(3), 1-6.

17.Zhang Y., Zhang J., Forest J., \& Chen C. (2018). The Negative and Positive Aspects of Employees' Innovative Behavior: Role of Goals of Employees and Supervisors. Frontiers in psychology, 9, 1871. doi:10.3389/ fpsyg.2018.01871.

\section{ДАННЫЕ ОБ АВТОРАХ}

Кутузова Анастасия Валерьевна, к.п.н., доцент

Красноярский институт железнодорожного транспорта филиал Иркутского университета путей сообщения ул. Ладо Кеиховели, 89, г. Красноярск, 660028, Российская Федеращия kutuzova_av@krsk.irgups.ru

Яркова Светлана Анатольевна, к.т.н., доцент

Красноярский институт железнодорожного транспорта филиал Иркутского университета путей сообщения ул. Ладо Кеиховели, 89, г. Красноярск, 660028, Российская Федеращия yarkova_sa@krsk.irgups.ru

Якимова Любовь Дмитриевна, к.т.н., доцент

Красноярский институт железнодорожного транспорта филиал Иркутского университета путей сообщения ул. Ладо Кеиховели, 89, г. Красноярск, 660028, Российская Федерачия

yakimova_ld@krsk.irgups.ru 
Мельникова Елена Викторовна, к.э.н., доцент

Сибирский государственный университет науки и технологий им. М.Ф. Решетнева просп. имени газеть Красноярский Рабочий, 31, г. Красноярск, 660037, Российская Федерация melena6921@mail.ru

\section{DATA ABOUT THE AUTHORS}

Kutuzova Anastasia Valerievna, Ph.D., Associate Professor

Krasnoyarsk Institute of Railway Transport - branch of the Irkutsk University of Railway Transport 89, Lado Ketskhoveli Str., Krasnoyarsk, 660028, Russian Federation

kutuzova_av@krsk.irgups.ru

Yarkova Svetlana Anatolievna, Ph.D., Associate Professor

Krasnoyarsk Institute of Railway Transport-branch of the Irkutsk University of Railway Transport

89, Lado Ketskhoveli Str., Krasnoyarsk, 660028, Russian Federation

yarkova_sa@krsk.irgups.ru

Yakimova Lyubov Dmitrievna, Ph.D., Associate Professor

Krasnoyarsk Institute of Railway Transport - branch of the Irkutsk University of Railway Transport

89, Lado Ketskhoveli Str., Krasnoyarsk, 660028, Russian Federation

yakimova_ld@krsk.irgups.ru

Melnikova Elena Viktorovna, Ph.D., Associate Professor Siberian State University of Science and Technology 31, newspaper Krasnoyarsk Worker ave., Krasnoyarsk, 660037, Russian Federation melena6921@mail.ru 